\title{
Prevalence of Incretin-Mimetic and Sodium-Glucose- Transporter-2-Inhibitor Therapy in German Hospitalized Type-2 Diabetics Following Myocardial Revascularization: An Observational Study
}

\author{
Rainer U. Pliquett (D) - Linda Golle · Andreas Wienke • \\ Matthias Girndt
}

Received: September 5, 2020 / Accepted: October 21, 2020 / Published online: November 16, 2020

(C) The Author(s) 2020

\begin{abstract}
Introduction: Real-world data indicate that sodium glucose transporter-2-inhibitor therapy and/or incretin mimetics are not widely prescribed in type-2 diabetics with atherosclerotic vascular disease. We hypothesized that incretinmimetic therapy is associated with better overall survival and 1-year mortality in type- 2 diabetics following myocardial revascularization.

Methods: Hospitalized type-2 diabetics of the Departments of Cardiology and Cardiothoracic Surgery (University Hospital Halle) who needed myocardial revascularization (PCI or CABG) in 2016 were included in this observational study: group 1 (incretin-mimetic therapy), group 2 (insulin therapy without incretin mimetics) and group 3 (oral diabetes medication without incretins or insulin). They were asked to mail in a questionnaire on medical therapy and outcomes 1.9 years following discharge. In non-responders, vital status was obtained by local registration offices 2.4 years after discharge.
\end{abstract}

R. U. Pliquett $(\bowtie) \cdot$ L. Golle · M. Girndt Department of Internal Medicine II, University Hospital of the Martin Luther University HalleWittenberg, Halle, Germany e-mail: rpliquett@endothel.de

\section{A. Wienke}

Institute of Medical Epidemiology, Biometry and Informatics, Martin Luther University Halle-

Wittenberg, Halle, Germany
Results: Two hundred four patients were recruited in this study. At discharge, only 4.4\% of all type- 2 diabetics were on incretin mimetic, $39.7 \%$ on insulin and $55.9 \%$ on oral diabetes medication. At the time of follow-up (response rate: $44.1 \%)$, there was no change in terms of prevalence of incretin-mimetic therapy $(5.6 \%$ of responders). Prevalence of sodium glucose transporter-2-inhibitor therapy increased from $6.9 \%$ to $15.6 \%$ in responders. In-hospital mortality (group 1: $0 \%$, group 2: $0 \%$, group 3: $5.2 \%$; $p=0.092$ ), survival after discharge (group 1: $88.9 \%$, group 2: $86.4 \%$, group 3: $88.0 \%$; $p=0.942)$ and number of rehospitalizations within 12 months after discharge (group 1: 1.0 per capita, group 2: 1.0 , group $3: 1.1 ; p=0.697$ ) were similar among prespecified groups and between group 2 and 3. By 1.9-year follow-up, hypoglycemic events were more frequent in group $2(1.5 \pm 2.9)$ than in group $3(0.02 \pm 0.1$; $p=0.0001)$.

Conclusion: The prevalence of incretin mimetics and sodium-glucose-transporter- 2 inhibitors was low both during the index hospitalization and at a 1.9-year follow-up. When comparing group 2 and group 3 patients, survival and rehospitalizations were similar; hypoglycemic events occurred more often in insulin-treated diabetics than in the those without.

Keywords: Diabetes mellitus; Hypoglycemia; Incretin mimetics; Insulin; Sodium glucose transporter-2 inhibitors 


\section{Key Summary Points}

Why carry out this study?

The role of diabetes medications with a cardiovascular benefit is unclear in type- 2 diabetics following myocardial revascularization.

\section{What was the hypothesis of the study?}

In this prospective observational study, we hypothesized that incretin-mimetic therapy improves both survival and clinical outcomes in type- 2 diabetics having had myocardial revascularization in the year 2016 .

Mail-in questionnaires (1.9 years after discharge) and a survey of vital status by local registration offices ( 2.4 years after discharge) were used.

\section{What were the study outcomes/conclusions?}

In 204 included patients, $4.4 \%$ had incretin-mimetic therapy and $6.9 \%$ had a SGLT-2i therapy at index hospitalization; 1.9 years later, among responders to a questionnaire (response rate: $44.1 \%$ of 204 patients), $5.6 \%$ of the responders had incretin-mimetic therapy and $15.6 \%$ SGLT-2i therapy.

During hospitalization, six patients $(2.4 \%$ of 204) died. By 2.4 years after discharge, 25 more patients (12.2\% of 204) died.

\section{What was learned from the study?}

Initiation of incretin-mimetic therapy in high-risk diabetics after myocardial revascularization was low in this study. A survival analysis of type- 2 diabetics on incretin-mimetic therapy was not possible.

\section{DIGITAL FEATURES}

This article is published with digital features to facilitate understanding of the article. You can access the digital features on the article's associated Figshare page. To view digital features for this article go to https://doi.org/10.6084/m9. figshare.13118555.

\section{INTRODUCTION}

Revascularization strategies in diabetes patients presenting with significant obstructive coronary artery disease are characterized by a reduced patency rate after percutaneous coronary interventions (PCI) [1] and, when opting for coronary arterial bypass graft (CABG), by a higher mortality rate $[2,3]$, especially in insulin-treated diabetes patients [4]. Underlying mechanisms for this increased mortality are unclear. Hyperglycemia may promote infections following surgery [5]. In addition, hypoglycemic episodes with consecutive neuroendocrine activation represent an explanation for the increased mortality in diabetes patients $[6,7]$.

Incretin-mimetic therapy with or without an accompanying insulin therapy offers an adequate glycemic control, fewer hypoglycemic events and weight loss compared to insulin therapy without incretin mimetics [8, 9]. In addition, type- 2 patients in the liraglutide arm of the LEADER trial had reduced total mortality compared to their counterparts with placebo as an add-on therapy [10]. Likewise, type- 2 diabetes patients on the sodium-glucose transporter-2 inhibitor (SGLT-2i) empagliflozin had a prognostic benefit in the EMPA-REG Outcome trial [11]. However, the prescription rate of evidence-based diabetes medications for patients with atherosclerotic vascular disease still is very low [12]. 
In the present study, type-2-diabetes patients who had undergone a myocardial revascularization procedure were included. If no contraindication was present, the initiation of both a SGLT-2i and an incretin-mimetic therapy was mandated by evidence published in the literature prior to or during the time this study was conducted [10, 11]. In addition, during the hospitalization for myocardial revascularization, a new incretin-mimetic therapy with or without accompanying insulin therapy and a SGLT-2i therapy were recommended routinely by consulting clinical diabetologists. However, as the patients were hospitalized in the Department of Cardiothoracic Surgery or in the Department of Cardiology, the recommendations were not followed consistently. All therapeutic decisions were made by staff physicians of the Department of Cardiothoracic Surgery and the Department of Cardiology. In addition, the diabetologist's recommendation may or may not have been transmitted to the treating ambulatory care physician. In short, it is unclear whether or not recommendations to change diabetes therapy were followed in these highrisk patients. Interestingly, in a national comparison, the cardiovascular risk profile and the cardiovascular mortality were reported to be highest in the population of the federal German state, where the current study was conducted [13]. As a PCI or a CABG surgery was needed for the type- 2 diabetics in this observational study, the authors assumed that a diabetes therapy with cardiovascular benefit including incretinmimetic therapy and/or SGLT-2i therapy had been considered during the index hospitalization and/or by the time of a follow-up questionnaire, unless contraindications existed. Hypothetically, incretin-mimetic therapy improves overall survival and 1-year mortality, reduces rehospitalizations and decreases hypoglycemic episodes. To test this hypothesis, overall survival was the primary endpoint. Secondary endpoints were 1-year mortality, the number of rehospitalizations within 12 months after discharge and hypoglycemic events 6 months prior to a 2-year follow-up questionnaire.

\section{METHODS}

\section{Patients and Study Design}

All type-2 diabetics hospitalized in the Departments of Cardiology and Cardiothoracic Surgery of the University Hospital of the Martin Luther University Halle-Wittenberg, subjected to either PCI or CABG between 1 January 2016 and 31 December 2016, were identified in the hospital database using the respective diagnosis and intervention codes. The identified patients were included in prespecified groups of this prospective observational study if they passed the inclusion and exclusion criteria. 2 years after discharge. As a follow-up contact, study participants were asked to mail in a questionnaire on medical therapy, on rehospitalizations within 12 months following discharge and on the number of hypoglycemic episodes 6 months prior to the questionnaire. In non-responders, vital status was determined by an inquiry at the resident's registration offices in the patients' hometowns up to 2.4 years after discharge.

The institutional review board of the Martin Luther University Halle-Wittenberg approved this study (file number 2017-88). The need for individual patient information and signed informed consent was waived. The authors confirm that the study was performed in accordance with the Helsinki Declaration of 1964 and its later amendments.

\section{Inclusion Criteria}

- Hospitalized patients (male/female) with type-2 diabetes

- Need for myocardial revascularization (PCI or CABG surgery) during the index hospitalization

- Age: $\geq 18$ years

- Age $<75$ years

- Group-specific criteria applied at discharge of index hospitalization:

- Group 1: ongoing or new incretin-mimetic therapy with or without insulin, with or without oral diabetes medication and diet 
- Group 2: ongoing or new insulin therapy without incretin-mimetic therapy, with or without oral diabetes medication and diet

- Group 3: ongoing oral diabetes medication and diet without incretin-mimetic therapy, without insulin therapy

\section{Exclusion Criteria}

- Age $<18$ years

- Age $\geq 75$ years

- Gravidity

- Psychiatric disorder with lack of ability to provide an informed consent

- Known active cancer disease or curative care within $<5$ years

\section{Hypothesis}

We hypothesized that incretin-mimetic therapy with or without an accompanying insulin therapy is associated with (1) improved overall survival, (2) less 1-year mortality after discharge from the index hospitalization, (3) fewer rehospitalizations within 12 months after discharge and (4) fewer symptomatic, documented hypoglycemic episodes with blood glucose $<3.9 \mathrm{mmol} / \mathrm{l}$ [14] during the 6 months prior to a follow-up questionnaire. For hypothesis generation, groups 2 and 3 were compared to detect possible differences in outcome in type-2-diabetes patients with or without insulin therapy. Physicians and scientists involved in the analysis of this study were not responsible for therapy decisions.

\section{Statistics}

Results were given as mean \pm standard deviation for metric variables or as the absolute and relative frequencies for categorical variables of all patients. Comparisons among groups 1-3 (primary objective) and between group 2 and 3 (secondary objective) included the following variables: in-hospital mortality, survival after discharge, hypoglycemia $(<3.9 \mathrm{mmol} / \mathrm{l}$ or $<70 \mathrm{mg} / \mathrm{dl}$ ) rate during the index hospitalization and within 6 months prior to the follow- up questionnaire, and comparison of the cumulative daily insulin dose during the index hospitalization and at the time of the follow-up questionnaire. The Kolmogorov-Smirnov test was used to check for normal distribution of the values. Differences between the mean values of two evaluation groups were checked by Student's t-test (parametric data) or Mann-Whitney test (non-parametric data) and of more than two evaluation groups by the ANOVA test (parametric data) or Kruskal-Wallis test (nonparametric data) with post-hoc tests (Tukey or Dunn, where appropriate). The Kaplan-Meier method with log-rank (Mantel-Cox) test was performed for survival analysis. All data calculations were performed using SPSS software (version 21; IBM Corp., Armonk, NY, USA). Graphs were displayed using Graphpad software (Prism 8, La Jolla, CA, USA).

\section{RESULTS}

Two hundred four patients with type- 2 diabetes hospitalized for myocardial revascularization (PCI or CABG) were recruited in this observational study. During the index hospitalization, $6(2.9 \%)$ of 204 patients died (Table 1), and 25 $(12.3 \%)$ more of all patients died within 2.4 years after discharge (Table 2 ). When considering in-hospital mortality and mortality within the observational period of $2.4 \pm 0.3$ years after discharge, total mortality was $15.2 \%$ (31 of 204 patients). As a study goal, the survival rates after discharge were similar among groups: $88.9 \%$ for group 1, $86.4 \%$ for group 2 and $88.0 \%$ for group $3(p=0.942)$. The number of rehospitalizations within 12 months after discharge was similar among groups $(0.8$ per capita in group 1 [ 4 of 5 patients, data of 3 patients were not available], 1.0 per capita in group 2 (41 per 40 patients, data of 30 patients were not available) and 1.1 per capita in group 3 (73 per 64 patients, data of 31 patients were not available; $p=0.722)$. By $1.9 \pm 0.5$ years after discharge, 90 patients $(44.1 \%)$ mailed in a questionnaire regarding medical therapy; 83 patients $(40.7 \%)$ did not. 
Table 1 Baseline characteristics of 204 high-risk type-2 diabetes patients according to medical treatment: group 1 (incretin mimetics with or without insulin, with or without oral diabetes medication); group 2 (insulin with or without oral diabetes medication)); group 3 (oral diabetes medication)

\begin{tabular}{|c|c|c|c|c|c|c|c|c|c|c|c|c|c|}
\hline & \multicolumn{4}{|c|}{ Group 1} & \multicolumn{4}{|c|}{ Group 2} & \multicolumn{5}{|c|}{ Group 3} \\
\hline & $\% n$ & $n$ & Mean \pm SD & $n^{\mathrm{a}}$ & $\% n$ & $n$ & Mean \pm SD & $n^{\mathrm{a}}$ & $\% n$ & $n$ & Mean \pm SD & $n^{\mathrm{a}}$ & $p^{\mathbf{b}}$ \\
\hline Patients & 204 & & & & & & & & & & & & \\
\hline Patients per group & 4.4 & 9 & NA & NA & 39.7 & 81 & NA & NA & 55.9 & 114 & NA & NA & NA \\
\hline $\operatorname{Men}(n)$ & 2.0 & 4 & NA & NA & 29.4 & 60 & NA & NA & 43.6 & 89 & NA & NA & NA \\
\hline Women $(n)$ & 2.5 & 5 & NA & NA & 10.3 & 21 & NA & NA & 12.2 & 25 & NA & NA & NA \\
\hline Percutanous coronary intervention & 2.5 & 5 & NA & NA & 12.7 & 26 & NA & NA & 14.2 & 29 & NA & NA & 0.423 \\
\hline Coronary-artery bypass graft & 2.0 & 4 & NA & NA & 26.9 & 55 & NA & NA & 41.7 & 85 & NA & NA & 0.335 \\
\hline Duration of hospital stay (days) & NA & 9 & $9.9 \pm 3.6$ & 0 & NA & 81 & $13.6 \pm 12.3$ & 0 & NA & 114 & $11.8 \pm 7.7$ & 0 & 0.534 \\
\hline Age (years) & $\mathrm{NA}$ & 9 & $62.2 \pm 10.3$ & 0 & NA & 81 & $66.9 \pm 7.0$ & 0 & NA & 114 & $66.0 \pm 7.5$ & 0 & 0.474 \\
\hline Body mass index $\left(\mathrm{kg} / \mathrm{m}^{2}\right)$ & NA & 7 & $34.3 \pm 6.6$ & 2 & NA & 64 & $31.5 \pm 6.7$ & 17 & $\mathrm{NA}$ & 82 & $30.7 \pm 5.2$ & 32 & 0.572 \\
\hline HbAlc (\%) & NA & 6 & $8.2 \pm 1.8$ & 3 & NA & 37 & $7.7 \pm 1.7$ & 44 & NA & 48 & $6.7 \pm 1.5$ & 66 & 0.0003 \\
\hline Metformin & 2.9 & 6 & NA & 0 & 16.7 & 34 & NA & 0 & 26.0 & 53 & NA & 2 & 0.468 \\
\hline Dipeptidyl-pepti-dase-4 inhibitor & 1.0 & 2 & NA & 0 & 8.8 & 18 & NA & 0 & 11.3 & 23 & NA & 2 & 0.859 \\
\hline Sulfonylurea & 0 & 0 & NA & 0 & 3.4 & 7 & NA & 0 & 5.9 & 12 & NA & 2 & 0.807 \\
\hline glinides & 0 & 0 & NA & 0 & 0 & 0 & NA & 0 & 1.5 & 3 & NA & 2 & 0.266 \\
\hline $\begin{array}{l}\text { Sodium glucose transporter-2 } \\
\text { inhibitor }\end{array}$ & 1.0 & 2 & NA & 0 & 3.4 & 7 & NA & 0 & 2.5 & 5 & NA & 2 & 0.366 \\
\hline Cumulative daily insulin (units) & NA & 9 & $22.2 \pm 33.1$ & 0 & NA & 73 & $44.5 \pm 36.6$ & 8 & NA & 114 & 0 & 0 & $<0.0001$ \\
\hline $\begin{array}{l}\text { Hypoglycemic episodes } \\
\text { per patient }(n)\end{array}$ & NA & 9 & 0 & 0 & NA & 81 & $0.3 \pm 1.0$ & 0 & NA & 88 & $0.1 \pm 0.4$ & 26 & 0.131 \\
\hline In-hospital mortality & 0 & 0 & NA & 0 & 0 & 0 & NA & 0 & 2.9 & 6 & NA & 0 & 0.083 \\
\hline
\end{tabular}

${ }^{a}$ Number of patients, in whom the parameter was not available (missing data or no follow-up data)

b Comparison of Group 2 and Group 3

\section{Low Initiation Rate of Incretin-Mimetic and SGLT-2i Therapy in Cardiovascular High-Risk Patients with Type-2 Diabetes}

Following CABG surgery, two patients (1 group 2 patient and 1 group 3 patient) also received PCI during the index hospitalization. All other patients received either PCI or CABG as primary intervention as outlined in Table 1 . Only 4.4\% (9 of 204) of high-risk type- 2 diabetics investigated in this study were on an incretin-mimetic therapy. Likewise, only $6.9 \%$ (14 of 204) of cardiovascular high-risk patients had a SGLT-2i therapy during the index hospitalization. In contrast to the underlying assumption prior to this study, neither incretin-mimetic nor SGLT-2i therapy was widely prescribed by the time of the 1.9-year follow-up: incretin-mimetic therapy was used in $5.6 \%$ (5 of 90 responders), and SGLT-2i therapy was used in $15.6 \%$ (14 of 90 responders). Thus, due to the low initiation rate, group 1 patients cannot be compared to group 2 or group 3 patients. Tables 1 and 2 both present the prespecified groups of type- 2 diabetics with and without incretin-mimetic therapy at baseline and follow-up. However, for statistical analysis, only groups 2 and 3 were considered. 
Table 2 Clinical and laboratory parameters, patient outcomes at follow-up in 173 high-risk type-2 diabetes patients: group 1 (incretin mimetics with or without insulin, with or without oral diabetes medication); group 2 (insulin with or without oral diabetes medication') group 3 (oral diabetes medication)

\begin{tabular}{|c|c|c|c|c|c|c|c|c|c|c|c|c|c|}
\hline & \multicolumn{4}{|c|}{ Group 1} & \multicolumn{4}{|c|}{ Group 2} & \multicolumn{5}{|c|}{ Group 3} \\
\hline & $\% n$ & $n$ & Mean \pm SD & $n^{\mathrm{a}}$ & $\overline{\% n}$ & $n$ & Mean \pm SD & $n^{\mathrm{a}}$ & $\% n$ & $n$ & Mean \pm SD & $n^{\mathrm{a}}$ & $p^{\mathbf{b}}$ \\
\hline Patients & 198 & & & & & & & & & & & & \\
\hline $\begin{array}{l}\text { Patients per } \\
\text { group }\end{array}$ & 4.5 & 9 & NA & NA & 40.9 & 81 & NA & NA & 54.5 & 108 & $\mathrm{NA}$ & NA & NA \\
\hline $\operatorname{Men}(n)$ & 2.0 & 4 & NA & NA & 30.3 & 60 & NA & NA & 43.4 & 86 & NA & NA & NA \\
\hline Women $(n)$ & 2.5 & 5 & NA & NA & 10.6 & 21 & NA & NA & 11.1 & 22 & NA & NA & $\mathrm{NA}$ \\
\hline $\begin{array}{l}\text { Time to } \\
\text { follow-up } \\
\text { (years) }\end{array}$ & NA & 6 & $1.8 \pm 0.6$ & 2 & $\mathrm{NA}$ & 38 & $2.0 \pm 0.5$ & 32 & NA & 46 & $1.8 \pm 0.4$ & 49 & 0.034 \\
\hline $\begin{array}{l}\text { Time to last } \\
\text { contact } \\
\text { (years) }\end{array}$ & NA & 2 & $2.3 \pm 0.4$ & NA & $\mathrm{NA}$ & 32 & $2.4 \pm 0.2$ & NA & NA & 49 & $2.4 \pm 0.3$ & NA & 0.222 \\
\hline Age (years) & NA & 8 & $62.4 \pm 9.9$ & 0 & $\mathrm{NA}$ & 70 & $68.9 \pm 7.1$ & 0 & NA & 95 & $67.4 \pm 7.4$ & 0 & 0.152 \\
\hline $\begin{array}{l}\text { Body mass } \\
\text { index }(\mathrm{kg} / \\
\left.\mathrm{m}^{2}\right)\end{array}$ & NA & 5 & $33.0 \pm 5.3$ & 3 & $\mathrm{NA}$ & 37 & $30.9 \pm 5.8$ & 33 & NA & 46 & $29.5 \pm 4.6$ & 49 & 0.120 \\
\hline HbAlc (\%) & NA & 5 & $8.0 \pm 0.6$ & 3 & NA & 35 & $7.3 \pm 1.1$ & 35 & NA & 36 & $6.8 \pm 1.0$ & 59 & 0.040 \\
\hline Metformin & 1.5 & 3 & NA & 2 & 9.1 & 18 & NA & 32 & 14.6 & 29 & NA & 51 & 0.118 \\
\hline $\begin{array}{l}\text { Dipeptidyl- } \\
\text { pepti-dase-4 } \\
\text { inhibitor }\end{array}$ & 0 & 0 & NA & 2 & 7.1 & 14 & NA & 32 & 8.6 & 17 & NA & 49 & $>0.999$ \\
\hline Sulfonylurea & 0 & 0 & NA & 2 & 0.5 & 1 & NA & 32 & 1.0 & 2 & $\mathrm{NA}$ & 49 & $>0.999$ \\
\hline Glinide & 0 & 0 & NA & 2 & 0 & 0 & NA & 32 & 0 & 0 & NA & 49 & NA \\
\hline $\begin{array}{l}\text { Sodium } \\
\text { glucose } \\
\text { transporter- } \\
2 \text { inhibitor }\end{array}$ & 1.0 & 2 & NA & 2 & 2.5 & 5 & NA & 32 & 3.5 & 7 & $\mathrm{NA}$ & 49 & $>0.999$ \\
\hline $\begin{array}{l}\text { Incretin- } \\
\text { mimetic } \\
\text { therapy }\end{array}$ & 2.0 & 4 & NA & 2 & 0 & 0 & NA & 32 & 0.5 & 1 & NA & 49 & $>0.999$ \\
\hline $\begin{array}{l}\text { Cumulative } \\
\text { daily insulin } \\
\text { (units) }\end{array}$ & NA & 6 & $36.0 \pm 36.5$ & 2 & NA & 37 & $44.7 \pm 34.6$ & 33 & NA & 46 & $5.3 \pm 13.6$ & 49 & $<0.0001$ \\
\hline $\begin{array}{l}\text { Change of } \\
\text { cumulative } \\
\text { daily insulin } \\
\text { (units) }\end{array}$ & NA & 6 & $15.7 \pm 19.1$ & 2 & $\mathrm{NA}$ & 33 & $6.4 \pm 31.3$ & 37 & NA & 45 & $5.2 \pm 13.7$ & 50 & 0.172 \\
\hline
\end{tabular}


Table 2 continued

\begin{tabular}{|c|c|c|c|c|c|c|c|c|c|c|c|c|c|}
\hline & \multicolumn{4}{|c|}{ Group 1} & \multicolumn{4}{|c|}{ Group 2} & \multicolumn{5}{|c|}{ Group 3} \\
\hline & $\% n$ & $n$ & Mean \pm SD & $n^{\mathrm{a}}$ & $\% n$ & $n$ & Mean \pm SD & $n^{\mathrm{a}}$ & $\% n$ & $n$ & Mean \pm SD & $n^{\mathrm{a}}$ & $p^{\mathbf{b}}$ \\
\hline $\begin{array}{c}\text { Hypoglycemic } \\
\text { episodes per } \\
\text { patient }(n)\end{array}$ & NA & 6 & $0.2 \pm 0.4$ & 2 & NA & 37 & $1.5 \pm 2.9$ & 33 & NA & 46 & $0.02 \pm 0.1$ & 49 & 0.0001 \\
\hline $\begin{array}{l}\text { 1-year } \\
\text { mortality } \\
\text { after } \\
\text { discharge }\end{array}$ & 0.5 & 1 & $\mathrm{NA}$ & 0 & 3.5 & 7 & NA & 0 & 4.0 & 8 & $\mathrm{NA}$ & 0 & 0.321 \\
\hline $\begin{array}{l}\text { Mortality over } \\
2.4 \text { years } \\
\text { after } \\
\text { discharge }\end{array}$ & 0.5 & 1 & NA & 0 & 5.6 & 11 & NA & 0 & 4.0 & 13 & $\mathrm{NA}$ & 0 & 0.827 \\
\hline
\end{tabular}

${ }^{a}$ Number of patients, in whom the parameter was not available (missing data or no follow-up data)

${ }^{b}$ Comparison of Group 2 and Group 3

Survival After Discharge was Similar; Hypoglycemic Burden Was Higher in Type-2 Diabetics on Insulin Therapy Versus Type-2 Diabetics on Oral Diabetes Medication Alone

As Fig. 1 shows, survival after discharge was similar in insulin-treated type-2 diabetics (group 2) and type-2 diabetics on oral diabetes medication (group 3). Thirteen of 81 group 2 patients (16.0\%) and 8 of 114 group 3 patients (7.0\%) were affected by hypoglycemic episodes during the index hospitalization (Table 1). Group 1 patients were not affected by hypoglycemic episodes during the index hospitalization. Within the 6 months prior to followup, the hypoglycemic burden was more pronounced: 1 of 6 group 1 patients (16.7\%), 10 of 37 group 2 patients (27.0\%) and 1 of 46 group 3 patients $(2.1 \%)$ reported one or more hypoglycemic episodes during the 6 months prior to the follow-up questionnaire (Table 2). Of note, after inclusion of study patients on sulfonylurea medication in group 2, the hypoglycemic burden was increased in group 2 during the index hospitalization (Table 3), it remained high at the 1.9-year follow-up (Table 4).

\section{Improvement of Hba1c at the Expense of More Hypoglycemic Episodes in Type-2 Diabetics on Insulin Therapy Versus Oral Diabetes Medication Alone}

When comparing groups 2 and 3 directly, the HbA1c was higher in group 2 than in group 3 at baseline (group 2: $7.7 \pm 1.7$, group 3: $6.7 \pm 1.5$, $p=0.0003)$, and the number of hypoglycemic events was similar (group 2: $0.3 \pm 1.0$, group 3: $0.1 \pm 0.4, p=0.131$ ). By the time of follow-up questionnaire, the number of hypoglycemic events was five times higher than at baseline in group 2, while it remained low in group 3 (group 2: $1.5 \pm 2.9, \quad$ group 3: $0.02 \pm 0.1$, $p=0.0001)$. HbA1c remained higher in group 2 than in group 3 (group 2: $7.3 \pm 1.1$, group 3: $6.8 \pm 1.0, p=0.040)$. Strikingly, despite insulin reduction to 0 units per day in 6 of 37 responders in group $2(16.2 \%)$, the average insulin 


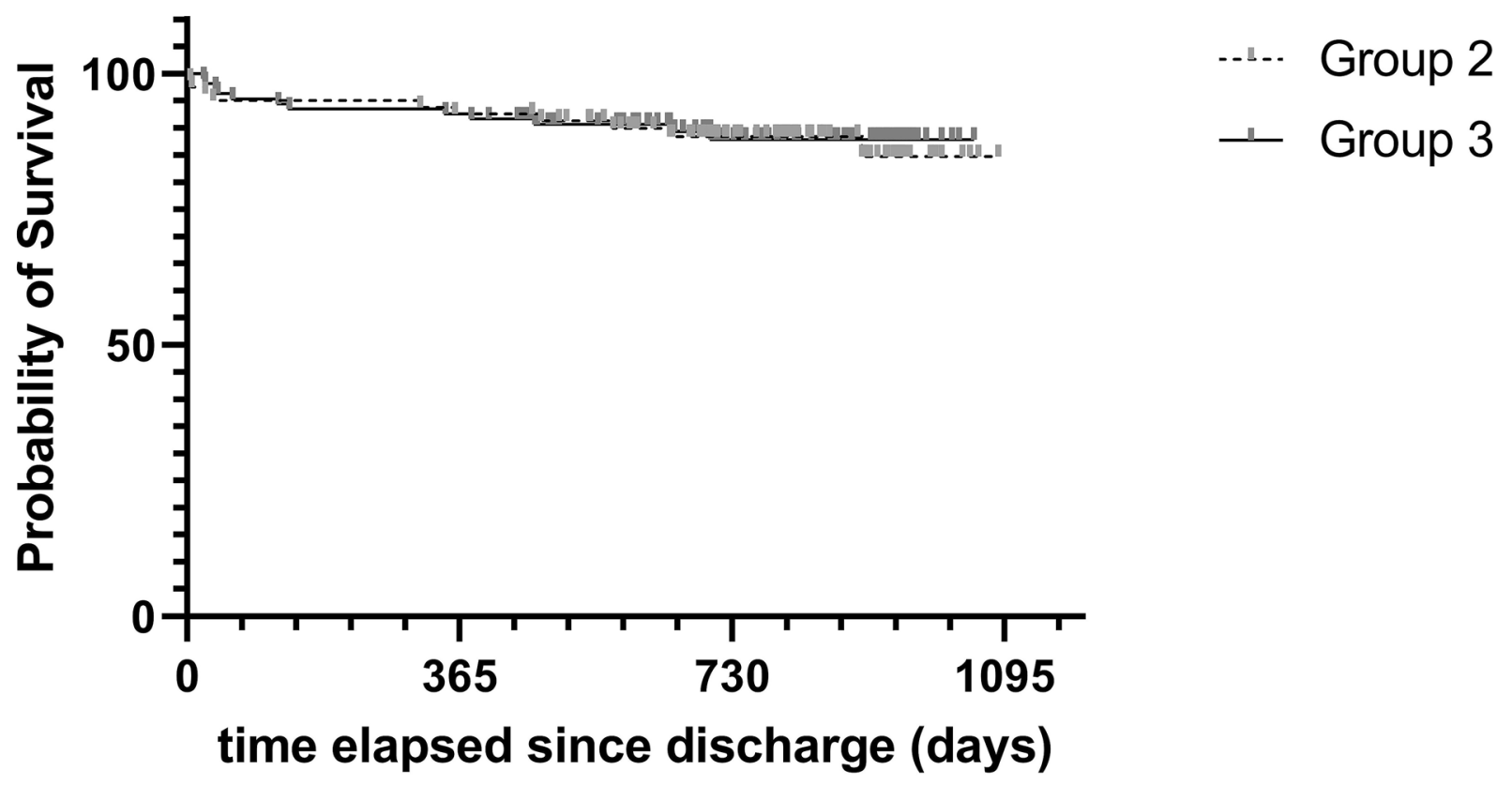

\section{log-rank (Mantel-Cox) test: $p$ value:0.983}

Fig. 1 Survival of diabetics with (group 2) and without insulin (group 3) following PCI or CABG. Kaplan-Meier method with log-rank (Mantel-Cox) test was performed for survival analysis in all three patient groups

dose per capita was increased by the follow-up in group 2 patients. Maximum daily cumulative insulin dose was 112 units per day; incretin mimetics were not introduced in group 2 . In group 3, insulin was newly introduced in in 8 of 46 responders $(17.4 \%)$ with a maximum daily cumulative insulin dose of 62 units per day.

\section{DISCUSSION}

Surprisingly, diabetes therapies with a proven cardiovascular benefit including SGLT-2i and incretin-mimetic therapy were not introduced adequately in type- 2 diabetics having had PCI or CABG surgery. When accounting for the missing follow-up data, the prevalence of both SGLT-2i and incretin-mimetic therapy likely would have doubled, which still is inadequate. Clearly, SGLT-2i and incretin-mimetic therapy were indicated in all study participants without contraindications. In fact, the financial burden for necessary cardiovascular medications is dwarfed by the comparison to PCI- or CABGrelated costs during the index hospitalization. Possible reasons for not using the diabetes medications with proven cardiovascular benefits may be reimbursement issues and the national Guideline on Therapy for Type-2 Diabetes, which had not been updated after completion of the LEADER [10] and Empareg Outcome trials [11] during the time of this study. In addition, the focus of therapy during hospitalization may have been the PCI or CABG surgery. The resulting case of "clinical inertia" or lack of treatment intensification in patients according to evidence-based goals for care and, simultaneously, the disparity in outcomes of myocardial infarction within Germany [15] need to be investigated further.

As a main result, symptomatic, documented hypoglycemic episodes occurred more often in group 2 patients on insulin therapy than in group 3 patients at follow-up 1.9 years after 
Table 3 Baseline characteristics of 204 high-risk type-2 diabetes patients according to medical treatment: group 1 (incretin mimetics with or without insulin, with or without oral diabetes medication); group 2 (insulin with or without oral diabetes medication or patients on sulfonylurea without insulin); group 3 (oral diabetes medication without sulfonylurea)

\begin{tabular}{|c|c|c|c|c|c|c|c|c|c|c|c|c|c|}
\hline & \multicolumn{4}{|c|}{ Group 1} & \multicolumn{4}{|c|}{$\begin{array}{l}\text { Group } 2+\text { sulfonylurea- } \\
\text { treated type } 2 \text { diabetics }\end{array}$} & \multicolumn{5}{|c|}{$\begin{array}{l}\text { Group } 3 \text { - sulfonylurea-treated type } 2 \\
\text { diabetics }\end{array}$} \\
\hline & $\% n$ & $n$ & Mean \pm SD & $n^{\mathrm{a}}$ & $\% n$ & $n$ & Mean \pm SD & $n^{\mathrm{a}}$ & $\% n$ & $n$ & Mean \pm SD & $n^{\mathrm{a}}$ & $p^{\mathbf{b}}$ \\
\hline Patients & 204 & & & & & & & & & & & & \\
\hline Patients per group & 4.4 & 9 & $\mathrm{NA}$ & NA & 39.7 & 93 & NA & NA & 55.9 & 102 & NA & NA & NA \\
\hline $\operatorname{Men}(n)$ & 2.0 & 4 & NA & NA & 33.8 & 69 & NA & NA & 39.2 & 80 & NA & NA & NA \\
\hline Women $(n)$ & 2.5 & 5 & $\mathrm{NA}$ & NA & 11.8 & 24 & $\mathrm{NA}$ & NA & 10.8 & 22 & NA & NA & NA \\
\hline Percutanous coronary intervention & 2.5 & 5 & $\mathrm{NA}$ & NA & 13.7 & 28 & $\mathrm{NA}$ & NA & 13.2 & 27 & NA & NA & 0.335 \\
\hline Coronary-artery bypass graft & 2.0 & 4 & $\mathrm{NA}$ & NA & 31.9 & 65 & $\mathrm{NA}$ & NA & 36.8 & 75 & NA & NA & 0.634 \\
\hline Duration of hospital stay (days) & NA & 9 & $9.9 \pm 3.6$ & 0 & NA & 93 & $13.1 \pm 11.7$ & 0 & NA & 102 & $12.0 \pm 8.0$ & 0 & 0.713 \\
\hline Age (years) & NA & 9 & $62.2 \pm 10.3$ & 0 & NA & 93 & $67.1 \pm 6.8$ & 0 & NA & 102 & $65.7 \pm 7.8$ & 0 & 0.263 \\
\hline Body-mass index $\left(\mathrm{kg} / \mathrm{m}^{2}\right)$ & NA & 7 & $34.3 \pm 6.6$ & 2 & NA & 72 & $31.7 \pm 6.5$ & 21 & NA & 74 & $30.5 \pm 5.1$ & 28 & 0.267 \\
\hline HbAlc (\%) & NA & 6 & $8.2 \pm 1.8$ & 3 & NA & 40 & $7.6 \pm 1.7$ & 53 & NA & 45 & $6.8 \pm 1.5$ & 57 & 0.006 \\
\hline Metformin & 2.9 & 6 & NA & 0 & 19.6 & 40 & NA & 0 & 23.0 & 47 & NA & 2 & 0.664 \\
\hline Dipeptidyl-pepti-dase- 4 inhibitor & 1.0 & 2 & NA & 0 & 9.3 & 19 & NA & 0 & 10.8 & 22 & NA & 2 & 0.861 \\
\hline Sulfonyl urea & 0 & 0 & NA & 0 & 9.3 & 19 & NA & 0 & 5.9 & 0 & NA & 2 & NA \\
\hline Glinides & 0 & 0 & NA & 0 & 0 & 0 & NA & 0 & 1.5 & 3 & NA & 2 & 0.247 \\
\hline $\begin{array}{l}\text { Sodium glucose transporter-2 } \\
\text { inhibitor }\end{array}$ & 1.0 & 2 & $\mathrm{NA}$ & 0 & 4.4 & 9 & NA & 0 & 1.4 & 3 & NA & 2 & 0.074 \\
\hline Cumulative daily insulin (units) & NA & 9 & $22.2 \pm 33.1$ & 0 & NA & 85 & $38.2 \pm 37.3$ & 8 & NA & 102 & 0 & 0 & $<0.0001$ \\
\hline $\begin{array}{l}\text { Hypoglycemic episodes per patient } \\
\quad(n)\end{array}$ & NA & 9 & 0 & 0 & NA & 81 & $0.3 \pm 1.0$ & 0 & NA & 88 & $0.1 \pm 0.4$ & 26 & 0.024 \\
\hline In-hospital mortality & 0 & 0 & $\mathrm{NA}$ & 0 & 0 & 0 & NA & 0 & 2.9 & 6 & NA & 0 & 0.030 \\
\hline
\end{tabular}

${ }^{a}$ Number of patients, in whom the parameter was not available (missing data or no follow-up data)

b Comparison of Group 2 and Group 3

discharge. However, the basic therapy goal "hypoglycemia avoidance" was even missed in high-risk cardiovascular patients in this study during the index hospitalization (Table 1). Specifically, in surviving group 2 patients during the index hospitalization, the average rate of hypoglycemia per capita and percentage of patients affected by hypoglycemia were more than double compared to group 3 patients on oral diabetes medication. The hypoglycemic burden became worse during the 6 months prior to the follow-up questionnaire in group 2 . As a likely reason, the daily cumulative insulin dose went up in group 2 patients by the time of follow-up. The higher HbA1c in group 2 patients both during the index hospitalization and at follow-up may be due to an unstable glucose metabolism with hypoglycemic episodes followed by a reactive, post-hypoglycemic hyperglycemia. Future trials using continuous glucose monitoring may confirm or reject the hypothesis that post-hypoglycemic hyperglycemia represents one cause for an increased $\mathrm{HbA1c}$ in the face of hypoglycemic episodes in insulin-treated diabetics. Ultimately, the optimization of insulin therapy represents a conditio sine qua non to reduce the hypoglycemic burden in high-risk patients with 
Table 4 Clinical and laboratory parameters and patient outcomes at follow-up in 173 high-risk type- 2 diabetes patients: group 1 (incretin mimetics with or without insulin, with or without oral diabetes medication); group 2 (insulin with or without oral diabetes medication or patients on sulfonylurea without insulin); group 3 (oral diabetes medication without sulfonylurea)

\begin{tabular}{|c|c|c|c|c|c|c|c|c|c|c|c|c|c|}
\hline & \multicolumn{4}{|c|}{ Group 1} & \multicolumn{4}{|c|}{$\begin{array}{l}\text { Group } 2+\text { sulfonylurea- } \\
\text { treated type } 2 \text { diabetics }\end{array}$} & \multicolumn{5}{|c|}{$\begin{array}{l}\text { Group } 3 \text { - sulfonylurea-treated type } 2 \\
\text { diabetics }\end{array}$} \\
\hline & $\% n$ & $n$ & Mean \pm SD & $n^{\mathrm{a}}$ & $\% n$ & $n$ & Mean \pm SD & $n^{\mathrm{a}}$ & $\% n$ & $n$ & Mean \pm SD & $n^{\mathrm{a}}$ & $p^{\mathbf{b}}$ \\
\hline Patients & 198 & & & & & & & & & & & & \\
\hline $\begin{array}{l}\text { Patients per } \\
\text { group }\end{array}$ & 4.5 & 9 & NA & NA & 40.9 & 93 & NA & NA & 54.5 & 96 & NA & NA & NA \\
\hline $\operatorname{Men}(n)$ & 2.0 & 4 & NA & NA & 34.8 & 69 & NA & NA & 38.9 & 77 & NA & NA & NA \\
\hline Women $(n)$ & 2.5 & 5 & NA & NA & 12.1 & 24 & NA & NA & 9.6 & 19 & $\mathrm{NA}$ & NA & NA \\
\hline $\begin{array}{l}\text { Time to follow- } \\
\text { up (years) }\end{array}$ & NA & 6 & $1.8 \pm 0.6$ & 2 & NA & 46 & $2.0 \pm 0.5$ & 35 & NA & 38 & $1.8 \pm 0.5$ & 46 & 0.082 \\
\hline $\begin{array}{l}\text { Time to last } \\
\text { contact } \\
\text { (years) }\end{array}$ & NA & 2 & $2.3 \pm 0.4$ & NA & NA & 35 & $2.4 \pm 0.2$ & NA & NA & 46 & $2.4 \pm 0.3$ & NA & 0.284 \\
\hline Age (years) & NA & 8 & $62.4 \pm 9.9$ & 0 & NA & 81 & $69.1 \pm 6.8$ & 0 & NA & 84 & $67.1 \pm 7.6$ & 0 & 0.067 \\
\hline $\begin{array}{l}\text { Body mass } \\
\text { index }(\mathrm{kg} / \\
\left.\mathrm{m}^{2}\right)\end{array}$ & NA & 5 & $33.0 \pm 5.3$ & 3 & NA & 45 & $30.4 \pm 5.5$ & 36 & NA & 38 & $29.8 \pm 4.8$ & 46 & 0.347 \\
\hline HbAlc (\%) & NA & 5 & $8.0 \pm 0.6$ & 3 & NA & 43 & $7.2 \pm 1.1$ & 38 & NA & 28 & $6.7 \pm 0.9$ & 56 & 0.066 \\
\hline Metformin & 1.5 & 3 & NA & 2 & 11.1 & 22 & NA & 35 & 12.6 & 25 & NA & 48 & 0.118 \\
\hline $\begin{array}{l}\text { Dipeptidyl- } \\
\text { pepti-dase- } 4 \\
\text { inhibitor }\end{array}$ & 0 & 0 & NA & 2 & 7.6 & 15 & NA & 35 & 8.1 & 16 & NA & 46 & $>0.999$ \\
\hline Sulfonylurea & 0 & 0 & $\mathrm{NA}$ & 2 & 1.5 & 3 & NA & 35 & 0 & 0 & $\mathrm{NA}$ & 46 & 0.248 \\
\hline Glinide & 0 & 0 & $\mathrm{NA}$ & 2 & 0 & 0 & NA & 35 & 0 & 0 & $\mathrm{NA}$ & 46 & NA \\
\hline $\begin{array}{l}\text { Sodium glucose } \\
\text { transporter-2 } \\
\text { inhibitor }\end{array}$ & 1.0 & 2 & $\mathrm{NA}$ & 2 & 3.5 & 7 & NA & 35 & 2.5 & 5 & $\mathrm{NA}$ & 46 & $>0.999$ \\
\hline $\begin{array}{l}\text { Incretin- } \\
\text { mimetic } \\
\text { therapy }\end{array}$ & 2.0 & 4 & NA & 2 & 0 & 0 & NA & 35 & 0.5 & 1 & NA & 46 & 0.452 \\
\hline $\begin{array}{l}\text { Cumulative } \\
\text { daily insulin } \\
\text { (units) }\end{array}$ & NA & 6 & $36.0 \pm 36.5$ & 2 & $\mathrm{NA}$ & 45 & $37.1 \pm 35.4$ & 36 & NA & 38 & $6.0 \pm 14.8$ & 46 & $<0.0001$ \\
\hline
\end{tabular}


Table 4 continued

\begin{tabular}{|c|c|c|c|c|c|c|c|c|c|c|c|c|c|}
\hline & \multicolumn{4}{|c|}{ Group 1} & \multicolumn{4}{|c|}{$\begin{array}{l}\text { Group } 2+\text { sulfonylurea- } \\
\text { treated type } 2 \text { diabetics }\end{array}$} & \multicolumn{5}{|c|}{$\begin{array}{l}\text { Group } 3-\text { sulfonylurea-treated type } 2 \\
\text { diabetics }\end{array}$} \\
\hline & $\% n$ & $n$ & Mean \pm SD & $n^{\mathrm{a}}$ & $\% n$ & $n$ & Mean \pm SD & $n^{\mathrm{a}}$ & $\% n$ & $n$ & Mean \pm SD & $n^{\mathrm{a}}$ & $p^{b}$ \\
\hline $\begin{array}{l}\text { Change of } \\
\text { cumulative } \\
\text { daily insulin } \\
\text { (units) }\end{array}$ & NA & 6 & $15.7 \pm 19.1$ & 2 & NA & 40 & $5.5 \pm 28.4$ & 41 & NA & 38 & $6.0 \pm 14.8$ & 46 & 0.793 \\
\hline $\begin{array}{c}\text { Hypoglycemic } \\
\text { episodes per } \\
\text { patient }(n)\end{array}$ & NA & 6 & $0.2 \pm 0.4$ & 2 & NA & 45 & $1.3 \pm 2.7$ & 36 & NA & 38 & $0.03 \pm 0.2$ & 46 & 0.002 \\
\hline $\begin{array}{l}\text { 1-year mortality } \\
\text { after } \\
\text { discharge }\end{array}$ & 0.5 & 1 & NA & 0 & 4.0 & 8 & NA & 0 & 3.5 & 7 & NA & 0 & 0.445 \\
\hline $\begin{array}{l}\text { Mortality over } \\
2.4 \text { years after } \\
\text { discharge }\end{array}$ & 0.5 & 1 & NA & 0 & 6.1 & 12 & NA & 0 & 6.1 & 12 & NA & 0 & 0.936 \\
\hline
\end{tabular}

$\% n=$ percentage of all patients (at baseline: $n=204$, at follow-up: $n=198$ ) in whom parameter was present

a Number of patients in whom the parameter was not available (missing data or no follow-up data)

${ }^{b}$ Comparison of groups 2 and 3

type- 2 diabetes. In this regard, multiple strategies including self-empowerment classes for patients, a sugar-reduced diet to avoid hyperglycemic events as a rationale to increase insulin dosage and oral diabetes medication to partially reduce the daily cumulative insulin dose may help fight the occurrence of hypoglycemic episodes. In addition, a partial substitution of insulin by SGLT-2i and/or by incretinmimetic therapy would have alleviated the hypoglycemic burden as shown in the limited number of group 1 patients by the time of follow-up.

A strength of this observational study is the fact that cardiovascular "high risk" was unequivocally proven by the inclusion criteria "need for myocardial revascularization."

In groups 2 and 3, the group size was sufficiently high to account for non-responders to the questionnaire.

\section{Limitations}

A causative relationship cannot be established using an observational study design. Measurement of prevalence of medications was limited by the relatively high number of patients who did not send in the follow-up questionnaire. Medications were subject to changes by ambulatory care diabetologists and family physicians. The low patient number in group 1 precludes any analysis or conclusion with regard to mortality involving this patient group. In addition, adherence to prescribed medications was not determined.

\section{CONCLUSIONS}

At the time of follow-up, the prevalence of incretin-mimetic and SGLT-2i therapy was poor at $5.6 \%$ and $15.6 \%$, respectively. Self-reported hypoglycemic events occurred more often in 
insulin-treated diabetics than in those without. Future studies need to investigate whether an adequate initiation of incretin-mimetic and SGLT-2i therapy in high-risk cardiovascular diabetics, as advocated by the current ADA/ EASD consensus guideline for type- 2 diabetics with atherosclerotic vascular disease [16], closes the morbidity and mortality gap observed among German federal states.

\section{ACKNOWLEDGEMENTS}

We thank the participants of the study.

Funding. No external funding or external sponsorship was received for this study or publication of this article. As an organizational sponsor, Martin Luther University Halle-Wittenberg covered publication-related costs including the Journal's Rapid Service Fee.

Authorship. All named authors meet the International Committee of Medical Journal Editors (ICMJE) criteria for authorship for this article, take responsibility for the integrity of the work as a whole, and have given their approval for this version to be published.

Authorship Contributions. RUP conceived the study, participated in analysis and wrote the manuscript draft. From June 2018 on, affiliation changed to Carl Thiem Hospital Cottbus, Germany. LG gathered data, participated in analysis and gave critical input to the interpretation of data. From 2019, affiliation changed to the Department of Dermatology, Martin Luther University Halle-Wittenberg. AW analyzed data and gave expert advice on statistical issues and interpretation of data. MG provided funding and gave critical input to the data analysis and discussion. All authors reviewed the data and participated in the revision of the manuscript.

Prior Presentation. Results of this study were presented by LG at the Fourth Mering Symposium on Diabetes Technology and Prevention in Cottbus, Germany.
Disclosures. Rainer U. Pliquett, Linda Golle, Andreas Wienke and Matthias Girndt have nothing to disclose.

Compliance with Ethics Guidelines. The institutional review board of Martin Luther University Halle-Wittenberg approved this study (file number 2017-88). The need for an individual patient information and signed informed consent was waived. The authors confirm that the study was performed in accordance with the Helsinki Declaration of 1964 and its later amendments.

Data Availability. The datasets generated and/or analyzed during the current study are not publicly available due to hospital policy. They are, however, available from the corresponding author on reasonable request.

Open Access. This article is licensed under a Creative Commons Attribution-NonCommercial 4.0 International License, which permits any non-commercial use, sharing, adaptation, distribution and reproduction in any medium or format, as long as you give appropriate credit to the original author(s) and the source, provide a link to the Creative Commons licence, and indicate if changes were made. The images or other third party material in this article are included in the article's Creative Commons licence, unless indicated otherwise in a credit line to the material. If material is not included in the article's Creative Commons licence and your intended use is not permitted by statutory regulation or exceeds the permitted use, you will need to obtain permission directly from the copyright holder. To view a copy of this licence, visit http://creativecommons.org/licenses/by$\mathrm{nc} / 4.0 /$.

\section{REFERENCES}

1. Lima EG, Hueb W, Garcia RM, Pereira AC, Soares PR, Favarato D, Garzillo CL, D'Oliveira Vieira R, Rezende PC, Takiuti M, Girardi P, Hueb AC, Ramires JA, Kalil FR. Impact of diabetes on 10-year outcomes of patients with multivessel coronary artery disease 
in the Medicine, Angioplasty, or Surgery Study II (MASS II) trial. Am Heart J. 2013;166:250-7.

2. McAlister FA, Man J, Bistritz L, Amad H, Tandon P. Diabetes and coronary artery bypass surgery: an examination of perioperative glycemic control and outcomes. Diabetes Care. 2003;26:1518-24.

3. Ram E, Sternik L, Klempfner R, Iakobishvili Z, Fisman EZ, Tenenbaum A, Zuroff E, Peled Y, Raanani E. Type 2 diabetes mellitus increases the mortality risk after acute coronary syndrome treated with coronary artery bypass surgery. Cardiovasc Diabetol. 2020;19:86.

4. Kogan A, Ram E, Levin S, Fisman EZ, Tenenbaum A, Raanani E, Sternik L. Impact of type 2 diabetes mellitus on short- and long-term mortality after coronary artery bypass surgery. Cardiovasc Diabetol. 2018;17:151.

5. van den Berghe $G$, Wouters P, Weekers F, Verwaest C, Bruyninckx F, Schetz M, Vlasselaers D, Ferdinande $\mathrm{P}$, Lauwers $\mathrm{P}$, Bouillon R. Intensive insulin therapy in critically ill patients. $\mathrm{N}$ Engl J Med. 2001;345:1359-67.

6. The ADVANCE Collaborative Group. Intensive blood glucose control and vascular outcomes in patients with type 2 diabetes. $\mathrm{N}$ Engl J Med. 2008;358:2560-72.

7. The Action to Control Cardiovascular Risk in Diabetes Study Group. Effects of intensive glucose lowering in type 2 diabetes. $\mathrm{N}$ Engl J Med. 2008;358:2545-59.

8. Lingvay I, Pérez Manghi F, García-Hernández P, Norwood P, Lehmann L, Tarp-Johansen MJ, Buse JB, DUAL V Investigators. Effect of insulin glargine uptitration vs insulin degludec/liraglutide on glycated hemoglobin levels in patients with uncontrolled type 2 diabetes: the DUAL V randomized clinical trial. JAMA. 2016;315:898-907.

9. Billings LK, Doshi A, Gouet D, Oviedo A, Rodbard HW, Tentolouris N, Grøn R, Halladin N, Jodar E. Efficacy and safety of IdegLira versus basal-bolus insulin therapy in patients with type 2 diabetes uncontrolled on metformin and basal insulin: the DUAL VII randomized clinical trial. Diabetes Care. 2018;41:1009-16.
10. Marso SP, Daniels GH, Brown-Frandsen K, Kristensen P, Mann JF, Nauck MA, Nissen SE, Pocock S, Poulter NR, Ravn LS, Steinberg WM, Stockner M, Zinman B, Bergenstal RM, Buse JB. LEADER Steering Committee; LEADER trial investigators. N Engl J Med. 2016;375:311-22.

11. Zinman B, Wanner C, Lachin JM, Fitchett D, Bluhmki E, Hantel S, et al. Empagliflozin, cardiovascular outcomes, and mortality in type 2 diabetes. N Engl J Med. 2015;373:2117-28.

12. Hamid A, Vaduganathan $M$, Oshunbade A, Ayyalasomayajula KK, Kalogeropoulos AP, Lien LF, Shafi T, Hall M, Butler J. Antihyperglycemic therapies with expansions of US Food and Drug Administration indications to reduce cardiovascular events: prescribing patterns within an Academic Medical Center. J Cardiovasc Pharmacol. 2020. https://doi.org/10.1097/FJC.0000000000000864 (Online ahead of print).

13. Diederichs $C$, Neuhauser $H$, Kroll L, Lange $C$, Mensink G, Dornquast C, Heidemann C, ScheidtNave C, Busch M. Regional differences in the prevalence of cardiovascular risk factors in men and women in Germany. Bundesgesundheitsblatt Gesundheitsforschung Gesundheitsschutz. 2017;60:151-62.

14. American Diabetes Association Workgroup on Hypoglycemia. Defining and reporting hypoglycemia in diabetes. Diabetes Care. 2005;28(5): 1245-9.

15. Müller-Nordhorn J, Rossnagel K, Mey W, Willich SN. Regional variation and time trends in mortality from ischaemic heart disease: East and West Germany 10 years after reunification. J Epidemiol Commun Health. 2004;58:481-5.

16. Davies MJ, Dlessio DA, Fradkin J, Kernan WN, Mathieu C, Mingrone G, Rossing P, Tsapas A, Wexler DJ, Buse JB. CONSENSUS REPORT management of hyperglycaemia in type 2 diabetes, 2018. A consensusreport by the American Diabetes Association (ADA) and the European Association for the Study of Diabetes (EASD). Diabetologia. 2018;61: 2461-98. 